\title{
Ubiquitin ligase CHIP functions as an oncogene and activates the AKT signaling pathway in prostate cancer
}

\author{
LI CHENG $^{1,2^{*}}$, JIN ZANG $^{3 *}$, HAN-JUE DAI ${ }^{1,2},{\text { FENG } \mathrm{LI}^{3} \text { and FENG GUO }}^{4}$ \\ ${ }^{1}$ Department of Oncology, ${ }^{2}$ Center for Clinical Laboratory and ${ }^{3}$ Department of Urology, The First \\ Affiliated Hospital of Soochow University, Suzhou, Jiangsu 215006; ${ }^{4}$ Department of Oncology, \\ Nanjing Medical University Affiliated Suzhou Hospital, Suzhou, Jiangsu 215001, P.R. China
}

Received November 22, 2017; Accepted April 12, 2018

DOI: 10.3892/ijo.2018.4377

\begin{abstract}
Carboxyl terminus of Hsc-70-interacting protein (CHIP) is an E3 ubiquitin ligase that induces the ubiquitination and degradation of numerous tumor-associated proteins and serves as a suppressor or promoter in tumor progression. To date, the molecular mechanism of CHIP in prostate cancer remains unknown. Therefore, the present study investigated the biological function of CHIP in prostate cancer cells and obtained evidence that CHIP expression is upregulated in prostate cancer tissues. The CHIP vector was introduced into DU145 cancer cells and the cell biological behaviour was examined through a series of experiments, including cell growth, cell apoptosis and migration and invasion assays. The results indicated that the overexpression of CHIP in DU145 prostatic cancer cells promoted cell proliferation through activation of the protein kinase B (AKT) signaling pathway, which subsequently increased cyclin D1 protein levels and decreased p21 and p27 protein levels. The overexpression of CHIP significantly increased the migration and invasion of the DU145 cells, which is possible due to activation of the AKT signaling pathway and upregulation of vimentin. The expression level of CHIP was observed to be increased in human prostate cancer tissues compared with the adjacent normal tissue. Furthermore, the CHIP expression level exhibited a positively association with the Gleason score of the patents. These findings indicate that CHIP functions as an oncogene in prostate cancer.
\end{abstract}

\section{Introduction}

Prostate cancer is a malignancy that severely affects the health of men worldwide. In the United States, an estimated

Correspondence to: Dr Feng Guo, Department of Oncology, Nanjing Medical University Affiliated Suzhou Hospital, 16 Baita Road, Suzhou, Jiangsu 215001, P.R. China

E-mail: guofeng27@suda.edu.cn

${ }^{*}$ Contributed equally

Key words: CHIP, prostate cancer, proliferation, invasion, AKT
161,360 cases of prostate cancer were newly diagnosed in 2017, leading to prostate cancer ranking first among cancers for incidence rate and third for mortality rate (1). The incidence and mortality of prostate cancer have increased in China in recent years due to changes in lifestyle and the living environment. In China, prostate cancer is one of the 10 most common cancers in men, and upward trends in incidence and mortality rates have been observed (2). The majority of prostate cancer patients are at an advanced stage of cancer and have distant metastasis when they are diagnosed, making the disease difficult to treat (3). A good understanding of the molecular mechanism of the progression of prostate cancer is likely to aid its diagnosis and treatment.

Carboxyl terminus of Hsc-70-interacting protein (CHIP), encoded by the STIP1 homology and U-box containing protein 1 (STUB1) gene, contains three domains: A three tetratricopeptide repeat (TPR) domain at its $\mathrm{N}$-terminus, a U-box domain at its C-terminus, and a domain connecting the $\mathrm{N}$-terminus and $\mathrm{C}$-terminus together. The TPR domain, which links to the molecular chaperones Hsc70-Hsc70 and Hsc90, mediates protein-protein interactions. The U-box domain displays an E3 ubiquitin ligase activity between the chaperone and proteasome systems $(4,5)$. As a new co-chaperone, CHIP serves an important role in the folding, transport and degradation of proteins (6). CHIP is an E3 ubiquitin ligase that induces the ubiquitination and degradation of proteasomes and misfolded proteins, such as cystic fibrosis transmembrane conductance regulator $(7,8)$.

Substantial evidence indicates that CHIP is associated with the development, migration and invasion of cancer. Although the exact function of CHIP has not been elucidated, it is considered to be a tumor suppressor in the majority of tumors. In ovarian carcinoma, the overexpression of CHIP suppresses tumor progression by inhibiting the aerobic glycolysis that provides energy to tumor cells (9). In addition, CHIP overexpression significantly inhibits the growth of leukemia cells (10). Furthermore, CHIP decreases the migration and invasion abilities of gastric cancer cells to suppress the malignant transformation of the tumor via the regulation of the nuclear factor $\kappa$-light-chain-enhancer of activated B cells $(\mathrm{NF}-\kappa \mathrm{B})$ signaling pathway (11). However, CHIP has been ascribed as an oncogene in other tumors. A recent study revealed that CHIP overexpression markedly increased the 
viability of thyroid cancer cells and accelerated tumor growth in vivo (12). In another study, B-type hepatitis virus-associated hepatocellular carcinoma, CHIP overexpression exhibited a marked association with a larger tumor size and the presence of portal vein invasion (13).

The specific role of CHIP in the progression of prostate cancer remains unclear. In the present study, the biological function and potential mechanism of CHIP in the oncogenesis and progression of prostate cancer were explored. The effects of the forced introduction of CHIP into DU145 human prostatic cancer cells on various biological behaviors of the cells, including proliferation, apoptosis, migration and invasion, were investigated in vitro. The activation of the AKT (also known as protein kinase B) signaling pathway and pro-apoptotic protein levels in the CHIP-overexpressing cell lines were also explored. In addition, a tissue microarray of human prostate cancer was used to investigate the correlation of CHIP expression with Gleason score.

\section{Materials and methods}

Cell culture. The DU145 cell line was obtained from American Type Culture Collection (Manassas, VA, USA) and maintained in RPMI-1640 (cat. no. 1844368) with $10 \%$ fetal bovine serum (FBS, cat. no. 1428479) (both from Gibco; Thermo Fisher Scientific, Inc., Waltham, MA, USA), $100 \mathrm{U} / \mathrm{ml}$ penicillin, $100 \mu \mathrm{g} / \mathrm{ml}$ streptomycin and $2 \mathrm{mM}$ glutamine. The cells were cultured in a humidified atmosphere containing $5 \% \mathrm{CO}_{2}$ at $37^{\circ} \mathrm{C}$.

Transfection. The MSCV vector containing green fluorescent protein (GFP; a gift from Professor Yong Zhao, Institute of Zoology, Chinese Academy of Sciences) was used as the basis of a CHIP overexpression vector. The full-length coding sequence of human CHIP (hCHIP) was amplified by polymerase chain reaction (PCR) and cloned into the MSCV-GFP vector to form MSCV-GFP-hCHIP. The primers were designed using Primer-BLAST (https://www.ncbi.nlm.nih.gov/tools/primerblast/). Two primer sequences of CHIP were selected as follows: 5'-AAAAAGATCTGGCGGCATGAAGGGCAAGG-3' and 5'-GGGAACCTCAGTAGTCCTCCACCC-3'. A total of 3.2x10 phoenix A packaging cells (a gift from Professor Yong Zhao) were seeded in a 35-mm dish and transfected with $2 \mu \mathrm{g} \mathrm{MSCV}$ GFP-hCHIP or control vector (MSCV-GFP) and $1 \mu \mathrm{g}$ pCL-Amp (gift from Professor Yong Zhao) using Lipofectamine 2000 (cat. no. 11668-019; Invitrogen; Thermo Fisher Scientific, Inc.). The supernatants were collected after transfection for $48 \mathrm{~h}$ to infect $2 \times 10^{5}$ DU145 cells and provide DU145-control and DU145hCHIP cells. The individual clones were subsequently selected by $5 \mathrm{ng} / \mu \mathrm{l}$ puromycin for 2 weeks.

Reverse transcription-quantitative PCR (RT-qPCR). RT-qPCR was used to validate the effect of $S T U B 1$ gene overexpression. Total RNA was extracted from the cells using RNAiso Plus reagent (cat. no. 9109; Takara Bio, Inc., Otsu, Japan) and quantified. Then, $2 \mu \mathrm{g}$ RNA was converted into cDNA using Superscript M-MLV (cat. no. 28025-013; Invitrogen; Thermo Fisher Scientific, Inc.). The conditions were as follows: $25^{\circ} \mathrm{C}$ for $10 \mathrm{~min}, 37^{\circ} \mathrm{C}$ for $50 \mathrm{~min}$ and $70^{\circ} \mathrm{C}$ for $15 \mathrm{~min}$. qPCR was performed in triplicate using SYBR Premix Ex Taq II (cat. no. RR420L; Takara Bio, Inc.) with a LightCycler 480 System
(Roche Diagnostics, Basel, Switzerland). $\beta$-actin was used as an endogenous control. Primer sequences were as follows: $\beta$-actin, 5'-GCTACGAGCTGCCTGACGG-3' and 5'-TGTTGGCGT ACAGGTCTTTGC-3'; STUB1, 5'-GCCAAGGAGCAGCG GCTGAA-3' and 5'-CTCTCACGCTCCGCGGCAAT-3'. The house- keeping gene ( $\beta$-actin) and the target genes were reverse transcribed together in a single run. The thermocycling conditions were as follows: pre-incubation at $95^{\circ} \mathrm{C}$ for $30 \mathrm{sec}$, followed by 45 cycles of $95^{\circ} \mathrm{C}(30 \mathrm{sec}), 58^{\circ} \mathrm{C}(15 \mathrm{sec})$ and $72^{\circ} \mathrm{C}(20 \mathrm{sec})$. The relative expression levels of the target genes were quantified by the $2^{-\Delta \Delta C q}$ method (14).

Western blot analysis. Whole-cell extracts, nuclear extracts (NEs) and cytoplasmic extracts (CE) were prepared using suspension buffer (10 mM Tris- $\mathrm{HCl}, 0.1 \mathrm{M} \mathrm{NaCl}, 1 \mathrm{mM}$ EDTA) and proteinase inhibitor (cat. no. 11697498001; Roche Diagnostics, Mannheim, Germany) according to standard procedures. The total protein was measured with a micro BCA protein assay kit (cat. no. 23235; Thermo Fisher Scientific, Inc.). Then $30 \mu \mathrm{g}$ proteins were fractionated by $10 \%$ SDS-PAGE and transferred to nitrocellulose membranes. After blocking with milk for $1 \mathrm{~h}$ at $4^{\circ} \mathrm{C}$, the membranes were probed with different antibodies (Abs) with incubation overnight at $4^{\circ} \mathrm{C}$. The membranes were washed the next day and then incubated with appropriate secondary Abs $(1: 10,000)$ at $4^{\circ} \mathrm{C}$ overnight. IRDye 680CW (cat. no. 926-32222) and IRDye 800CW secondary Abs (cat. no. 926-32213) were obtained from LI-COR Biosciences (Lincoln, NE, USA). The bands were scanned using an Odyssey system (LI-COR Biosciences). Band densities were normalized to the $\beta$-actin or lamin $\mathrm{A} / \mathrm{C}$ loading control. Primary Abs against transcription factor p65 (RelA; sc-372), transcription factor RelB (RelB; sc-226), p105/p50 (sc-7178), p100/p52 (sc-298), proto-oncogene c-Rel (c-Rel; sc-70), laminA/C (sc-20681), urokinase-type plasminogen activator (uPA; sc-14019), TNF receptor-associated factor 2 (TRAF2; sc-876) and TNF receptor-associated factor 3 (TRAF3; sc-4729) were purchased from Santa Cruz Biotechnology, Inc. (Dallas, TX, USA). Abs against vimentin (CBL202) were purchased from EMD Millipore (Billerica, MA, USA). Abs against uPA receptor (UPAR; \#12713), B-cell lymphoma-2 (Bcl-2; \#2870), Bcl-extra large (Bcl-xL; \#2764), Bcl-2-like protein 11 (Bim; \#2933), BH3 interacting-domain death agonist (BID; \#2002), Bcl-2-associated death promoter (Bad; \#9239), p53 (\#9919), CHIP (\#2080), matrix metalloproteinase (MMP)2 (\#13132), MMP9 (\#13667), integrin $\beta 1$ (ITGB1; \#9699), keratin8/18 (\#4546), epithelial cell adhesion molecule (EpCAM; \#14452), N-cadherin (\#13116), phosphatase and tensin homolog (PTEN; \#9559) and glycogen synthase kinase (GSK)-3 $\beta$ (\#9315), the Cell Cycle Regulation Sample kit (\#9932) and phospho-Akt Pathway Antibody Sampler kit (\#9916) were purchased from Cell Signaling Technology, Inc. (Danvers, MA, USA). Abs against $\beta$-actin (AO1215a) were purchased from Abgent, Inc. (San Diego, CA, USA).

Cell growth assay. The xCelligence RTCA instrument (ACEA Biosciences, Inc., San Diego, CA, USA) was used to evaluate the growth of the cells. In this assay, $8.0 \times 10^{3}$ cells were seeded in each well in an E-plate and the impedance was continuously monitored for $72 \mathrm{~h}$. For each well, a 'cell index' was generated, which was determined by the number of cells seeded, 
the morphology and overall size of the cells, and the degree to which the cells interacted with the sensor surface. The cell index was continuously monitored by the system and data were collected and analyzed using RTCA 1.2 software (ACEA Biosciences, Inc.).

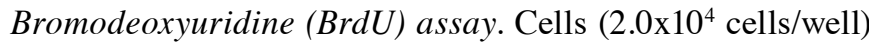
were seeded in a 96-well plate and cultured with fresh medium in a humidified atmosphere containing $5 \% \mathrm{CO}_{2}$ at $37^{\circ} \mathrm{C}$ for 24 h. BrdU from a BrdU Cell Proliferation kit (cat. no. 2750; EMD Millipore) was then added and the plate was incubated for $5 \mathrm{~h}$ at $37^{\circ} \mathrm{C}$. The medium was then removed and the cells were fixed at room temperature for $30 \mathrm{~min}$. Following removal of the fixing solution, the cells were washed twice with washing buffer, $100 \mu \mathrm{l} /$ well diluted anti-BrdU antibody was added, and the cells incubated for $1 \mathrm{~h}$ at room temperature. The wells were then washed prior to the addition of $100 \mu \mathrm{l} /$ well peroxidase conjugate followed by $100 \mu \mathrm{l} /$ well of TMB peroxidase substrate, with incubation for $30 \mathrm{~min}$ at room temperature following each addition. The reaction was stopped by the addition of stop solution and the optical density value at $450 \mathrm{~nm}(\mathrm{OD} 450)$ was measured.

Cell counting kit-8 (CCK-8) assay. Cell viability was measured using a CCK-8 assay (cat. no. CK04; Dojindo Molecular Technologies, Inc., Kumamoto, Japan). Cells (5.0x10 $0^{3}$ cells/well) were seeded into a 96 -well plate and incubated at $37^{\circ} \mathrm{C}$ for 24 , 48 and 72 h. RPMI-1640 medium was used as a blank control. Following incubation, $10 \mu \mathrm{l} \mathrm{CCK}-8$ solution was added to each well and the plate was continuously incubated at $37^{\circ} \mathrm{C}$ for $2 \mathrm{~h}$. The OD450 of each well was then monitored.

Cell cycle assay. Following culture for $48 \mathrm{~h}$, cells were washed thrice with ice-cold PBS and then fixed in cold $70 \%$ ethanol for $\geq 24 \mathrm{~h}$ at $4^{\circ} \mathrm{C}$. Single cell suspensions were then prepared, in which the DNA was stained using propidium iodide (PI; P4170; Sigma-Aldrich; Merck KGaA, Darmstadt, Germany) following the manufacturer's protocol. Cell cycle analysis was conducted using a FACSCalibur flow cytometer (BD Biosciences, Franklin Lakes, NJ, USA) with three independent experiments performed. The stained cells were analysed with BD CellQuest ${ }^{\mathrm{TM}}$ Pro software (BD Biosciences).

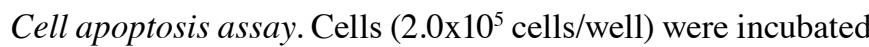
in a 6-well plate and cultured with fresh medium for 24, 48 and $72 \mathrm{~h}$. The cells were then washed thrice with ice-cold PBS and the APC-Annexin V Binding Apoptosis assay kit (cat. no. 22837; AAT Bioquest, Sunnyvale, CA, USA) was used to measure apoptosis according to the manufacturer's protocol.

Cell migration assay. A cell migration assay was performed using the xCelligence RTCA instrument with its CIM-plate. The upper chambers of the CIM-plate were supplemented with $4 \times 10^{4}$ cells/well in FBS-free RPMI-1640 medium. The lower chambers of CIM-plate were supplemented with RPMI-1640 medium containing $10 \%$ FBS. Following attachment, the impedance produced by cell migration towards the lower chamber was continuously monitored for $24 \mathrm{~h}$ by the system. The data were collected and analyzed by the RTCA 1.2 software.
A Transwell chamber (cat. no. 3422; Corning Incorporated, Corning, NY, USA) was also used to measure cell migration ability. The Transwell insert was supplemented with $4 \times 10^{4}$ cells/well in FBS-free RPMI-1640 medium, and RPMI-1640 medium containing 10\% FBS was added to the lower chamber. After $48 \mathrm{~h}$, the Transwell inserts were washed thrice with PBS and fixed in methylethanol for $\geq 20 \mathrm{~min}$. The Transwell inserts were then stained with crystal violet for $10 \mathrm{~min}$ at room temperature, washed and the remaining crystal violet-stained cells were gently removed with a cotton swab tipped applicator. The cells were counted under the light microscope (magnification, $\mathrm{x} 200$ ) in $\geq 5$ different fields of view to calculate the mean number of migrated cells.

Scratch healing assay. When the cells reached 80-90\% confluence, a pipette tip was used to wound the cells and fresh RPMI-1640 medium with 10\% FBS was applied. Wound healing was observed with a light microscope (System Microscope IX71) for $48 \mathrm{~h}$. The gap closure was observed at 24 and $48 \mathrm{~h}$, and compared with the width of the gap at $0 \mathrm{~h}$.

Cell invasion assays. A cell invasion assay was performed with the xCelligence RTCA instrument and CIM-plate as in the cell migration assay. The upper chambers of the CIM-plate were pre-coated with Matrigel (cat. no. 356234; BD Biosciences) and then supplemented with $6 \times 10^{4}$ cells/well in FBS-free RPMI-1640 medium. The lower chambers of the CIM-plate were supplemented with RPMI-1640 medium containing 10\% FBS. Following attachment, the impedance produced by cells invading through the Matrigel towards the lower chamber was continuously monitored for $24 \mathrm{~h}$ by the system. The data were collected and analyzed by the RTCA 1.2 software.

Transwell chambers were also used to measure cell invasion. Matrigel was added to the Transwell insert and solidified at $37^{\circ} \mathrm{C}$ for $4-6 \mathrm{~h}$ to form a thin gel layer. The Transwell insert was supplemented with $6 \times 10^{4}$ cells/well in FBS-free RPMI-1640 medium. The lower chamber was supplemented with RPMI-1640 medium containing 10\% FBS. After $48 \mathrm{~h}$, the Transwell inserts were washed thrice with PBS and fixed in methylethanol for $\geq 20 \mathrm{~min}$. The Transwell insert was stained with crystal violet for $10 \mathrm{~min}$ at room temperature. After that, the Transwell inserts were washed with PBS and the remaining crystal violet-stained cells were gently removed with a cotton swab tipped applicator. The cells were counted under a light microscope (magnification, $x 200$ ) in $\geq 5$ different fields of view to calculate the mean number of invaded cells.

Tissue microarray. CHIP expression was examined by immunohistochemistry (IHC), and hematoxylin and eosin (H\&E) staining was also examined. A tissue microarray of human prostate cancer (HProA180PG04) was obtained from Shanghai Outdo Biotech Co., Ltd. (Shanghai, China). All the tissue specimens in this microarray, which included prostate cancer tissue and tissue adjacent to the cancer, were obtained from 90 patients diagnosed with prostate cancer. Tissue IHC was performed using anti-CHIP antibody (\#2080; Cell Signaling Technology, Inc.) according to the instructions of the GTVision III Detection System/Mo \& Rb IHC kit (GK500705; Dako; Agilent Technologies, Inc., Santa Clara, CA, USA). CHIP expression was graded on a scale of + to ++++ according 
A

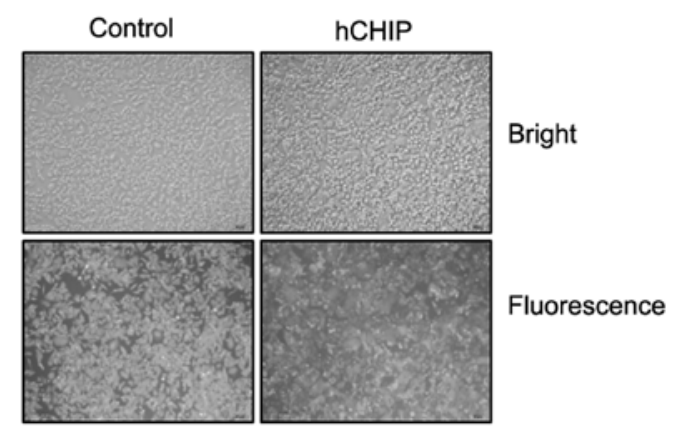

C

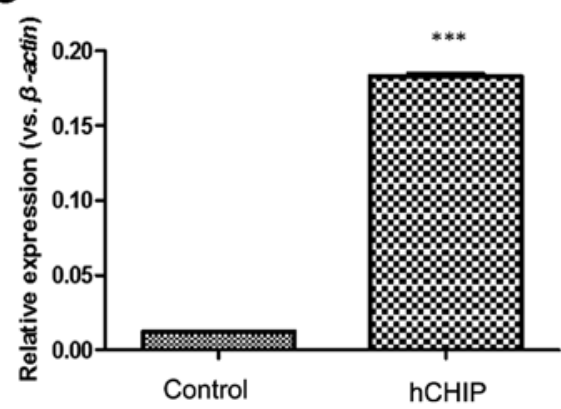

B
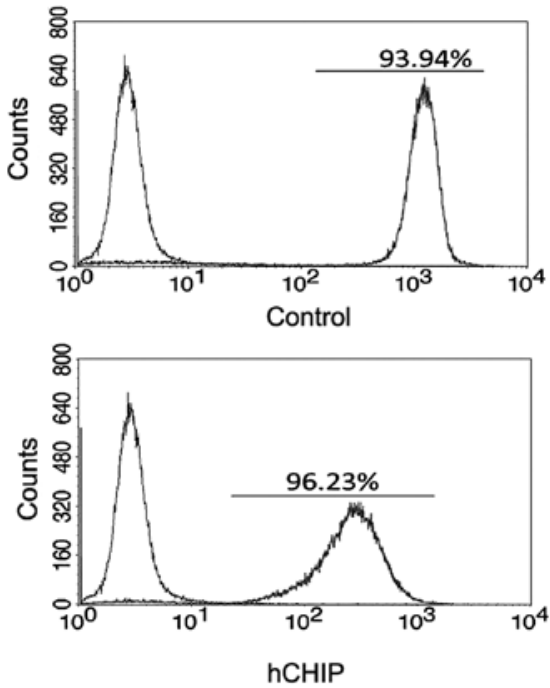

$\mathrm{D}$

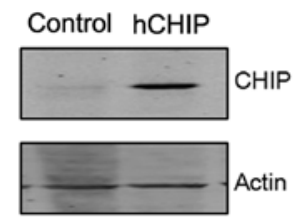

Figure 1. Establishment of a CHIP-overexpressing DU145 cell line. (A) Representative images of GFP signals in the two established cell lines. GFP signals in DU145-control and DU145-hCHIP cells were observed using fluorescence microscopy. The upper two images are bright field images, while the lower two images are fluorescent field images (original magnification, $\mathrm{x} 40$ ). (B) The GFP signals of the DU145-control and DU145-hCHIP cells were examined by flow cytometry. (C) CHIP mRNA expression between the two established cell lines. $\beta$-actin normalized gene expression, measured in triplicates is displayed. Significant differences were indicated ${ }^{* * * *} \mathrm{P}<0.0001$ vs. control; Student's t-test). (D) Protein levels of CHIP expression in the DU145-control and DU145-hCHIP cell lines determined by western blotting. The level of each protein was normalized against actin. CHIP, carboxyl terminus of Hsc-70-interacting protein; hCHIP, human CHIP; GFP, green fluorescent protein.

to the staining intensity of the cells. Positive CHIP staining in each specimen was evaluated in the cytoplasm follows: + , weak staining, light yellow; ++ , moderate staining, light yellow brown; +++, strong staining, brown; ++++, extreme staining, dark brown. The grades were divided into two groups: low (+/++) and high $(+++/++++)$.

Statistical analysis. All experiments were repeated at least three times. Data are expressed as the mean \pm standard deviation. Statistical comparisons were performed by Student's t-test. The clinical characteristics of the subjects were expressed as the mean \pm standard deviation. Chi-square test was used to analyse the associations between qualitative clinicopathological variables and CHIP expression. $\mathrm{P}<0.05$ was considered to indicate a statistically significant difference. Data were analyzed with the statistical analysis software SPSS 18.0 for Windows (SPSS Inc., Chicago, IL, USA).

\section{Results}

Establishing a CHIP-overexpressing cell line. To understand the role of CHIP in DU145 prostate cancer cells, a plasmid overexpressing CHIP was constructed and transfected into DU145 cells. When observed using fluorescence microscopy, the DU145-control and DU145-hCHIP cells presented strong GFP signals (Fig. 1A). The percentages of GFP-positive cells, detected by flow cytometry, in the DU145-control and DU145-hCHIP cells were 93.94 and 96.23\%, respectively (Fig. 1B). As shown in Fig. 1C, the CHIP mRNA expression of selected clones, which were expanded for 2 weeks, was examined by RT-qPCR. The expression of CHIP mRNA was significantly increased in the DU145-hCHIP cells compared with the DU145-control cells. The protein levels of CHIP in the DU145-hCHIP cells were also observed to be markedly increased compared with those in the DU145-control cells when evaluated using western blotting (Fig. 1D). The results indicated that the DU145 prostate cancer cell line overexpressing CHIP was established successfully.

CHIP overexpression promotes DU145 cell growth. To investigate the effect of CHIP overexpression on cell growth, the real-time xCelligence system was used. The DU145 cells overexpressing CHIP grew faster than the DU145-control cells, and a significant difference was observed between the two established cell lines during the 72-h continuous monitoring (Fig. 2A). A CCK8 assay and BrdU proliferation assay were performed to investigate the proliferation capability of the DU145 cells. In the CCK8 assay, the OD450 values of the 

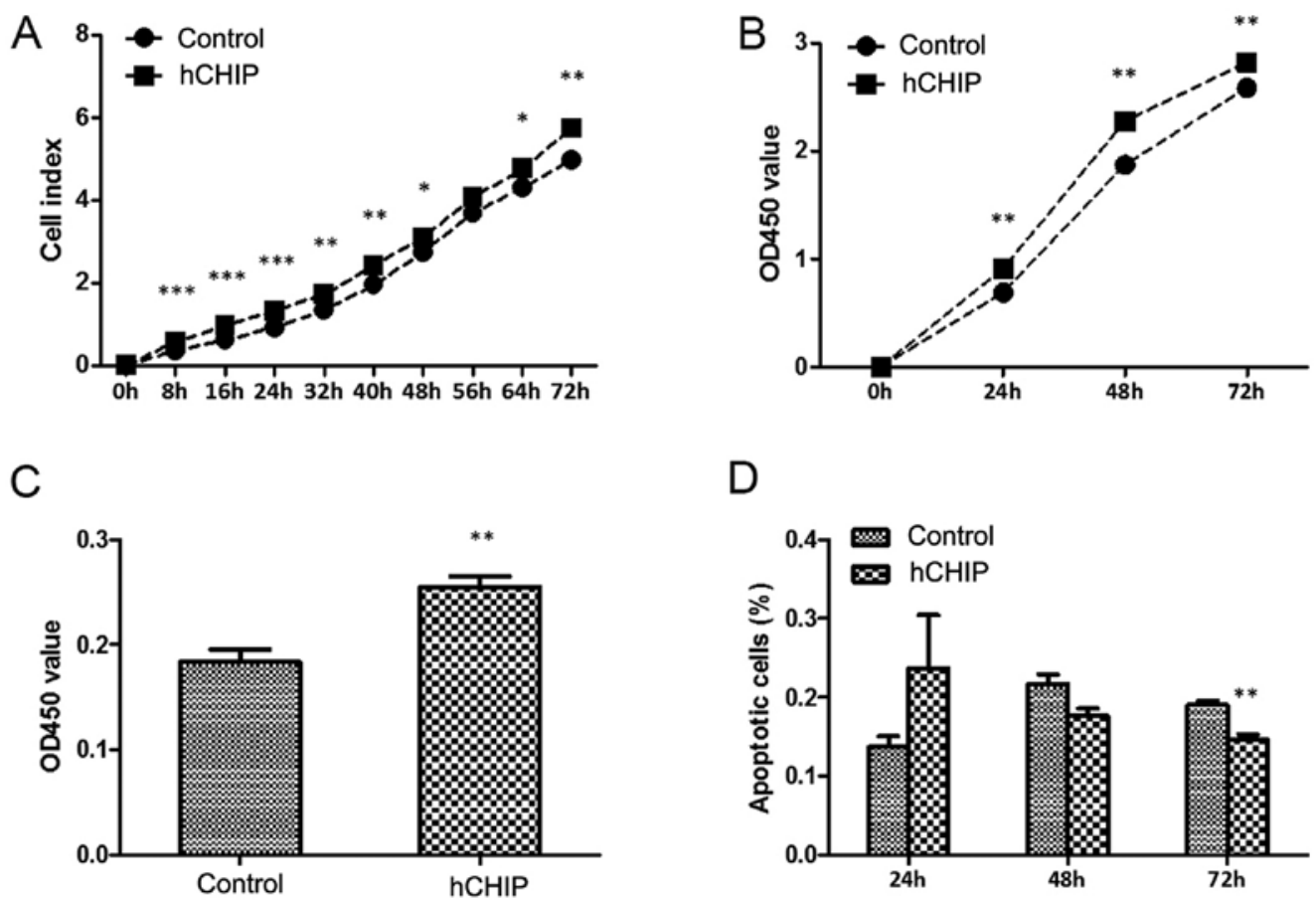

Figure 2. CHIP overexpression promotes DU145 cell growth. (A) Cell growth curves for DU145-control and DU145-hCHIP cells were constructed using the xCelligence system. Each plate was inoculated with $8 \times 10^{3}$ cells and cell growth was examined during a 72 -h continuous monitoring period $\left({ }^{*} \mathrm{P}<0.05,{ }^{* * *} \mathrm{P}<0.01\right.$ and ${ }^{* * *} \mathrm{P}<0.001$; Student's t-test). (B) CCK-8 assay was used to evaluate cell proliferation ${ }^{* * *} \mathrm{P}<0.01$; Student's t-test). (C) BrdU assay was used to further examine cell proliferation. The bar chart represents the OD450 value of the two established cell lines. Significant differences are indicated ("* $\mathrm{P}<0.01 ;$ Student's t-test). (D) Flow cytometry was used to quantitatively evaluate the apoptotic cells. The bar chart represents the percentages of apoptotic cells of the two established cell lines. Significant differences are indicated $\left({ }^{* *} \mathrm{P}<0.01\right.$; Student's t-test). CHIP, carboxyl terminus of Hsc-70-interacting protein; hCHIP, human CHIP; CCK-8, cell counting kit-8; BrdU, bromodeoxyuridine.

DU145-control group were $0.690 \pm 0.068,1.872 \pm 0.174$ and $2.584 \pm 0.099$ at 24,48 and $72 \mathrm{~h}$, respectively compared with $0.980 \pm 0.076,2.276 \pm 0.127$ and $2.821 \pm 0.047$, respectively in the DU145-hCHIP group (Fig. 2B). The proliferation of the DU145hCHIP cells was much greater than that of the DU145-control cells and statistically significant differences were detected between the two established cell lines during the 72-h continuous monitoring. Similar results were obtained in the BrdU proliferation assay. The OD450 value of the DU145-control cells was $0.184 \pm 0.023$ and that of the DU145-hCHIP cells was $0.255 \pm 0.020$ (Fig. 2C). The proliferation of the DU145 cells with ectopic CHIP expression was significantly increased. Cellular apoptosis was measured by flow cytometry and the results are shown in Fig. 2D. The DU145-control cells comprised $0.203 \pm 0.025,0.210 \pm 0.020$ and $0.200 \pm 0.010 \%$ apoptotic cells at 24,48 and $72 \mathrm{~h}$, respectively, whereas the DU145-hCHIP cells comprised $0.173 \pm 0.025,0.177 \pm 0.015$ and $0.143 \pm 0.015 \%$ apoptotic cells at 24,48 and $72 \mathrm{~h}$. Apoptosis was reduced in the DU145-hCHIP cells compared with the DU145-control cells, and a statistically significant difference in the frequencies of apoptotic cells was detected between the two types of cells at $72 \mathrm{~h}$. Considered together, these results indicate that CHIP overexpression accelerated the growth of DU145 cells, likely due to the promotion of cellular proliferation and inhibition of cellular apoptosis.

CHIP regulates proliferation- and apoptosis-associated proteins. Western blotting results for the cells are presented in Fig. 3. The levels of proteins associated with the NF- $\kappa \mathrm{B}$ signaling pathway were examined. As shown in Fig. 3B, there were no evident changes in the expression of RelA, RelB, p50, p52 and c-Rel in NE and CE portions of the DU145-hCHIP cells compared with the DU145-control cells. The protein levels of TRAF2 and TRAF3, which are upstream molecules of the NF- $\kappa$ B signaling pathway, were also examined. TRAF2 positively regulates canonical and non-canonical $N F-\kappa B$ activity and TRAF3 negatively regulates non-canonical $\mathrm{NF}-\kappa \mathrm{B}$ activity (15). In the present study, there were no clear differences in the expression of TRAF2 and TRAF3 between the DU145-hCHIP cells and the DU145-control cells.

AKT signaling molecules were also examined by western blotting to investigate whether they are involved in the altered cellular proliferation induced by the expression of CHIP. As shown in Fig. 3C, the expression levels of total AKT, p-AKT-473, p-AKT-308, p-PTEN, p-c-Raf, GSK-3 $\beta$ and p-GSK-3 $\beta$ were higher in the DU145-hCHIP cells compared with the DU145control cells. The overexpression of CHIP led to a reduction in the expression level of PTEN. However, the phosphorylation levels of 3-phosphoinositide-dependent protein kinase 1 were similar in the two types of DU145 cells (Fig. 3C). The protein levels of $\mathrm{Bcl}-2$, an anti-apoptotic protein, were markedly increased in the DU145-hCHIP cells compared with the DU145-control cells. By contrast, the protein levels of Bim, a pro-apoptotic protein were reduced in the DU145-hCHIP cells (Fig. 3D). Together, these results indicate that CHIP overexpression led to activation of the AKT signaling pathway. In addition, the promoted expression of anti-apoptotic proteins, such as Bcl-2, and suppressed expression of pro-apoptotic proteins, such as Bim, may have contributed to the reduction of apoptosis in the DU145-hCHIP cells. 
A

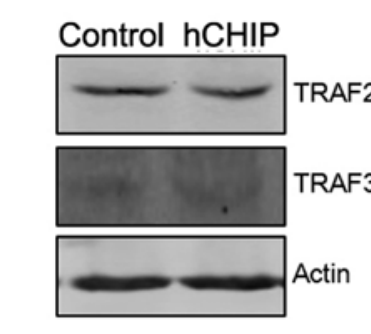

C

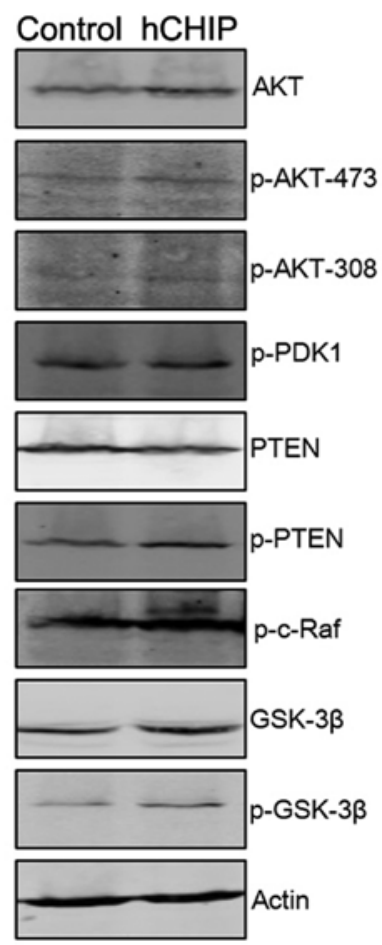

B

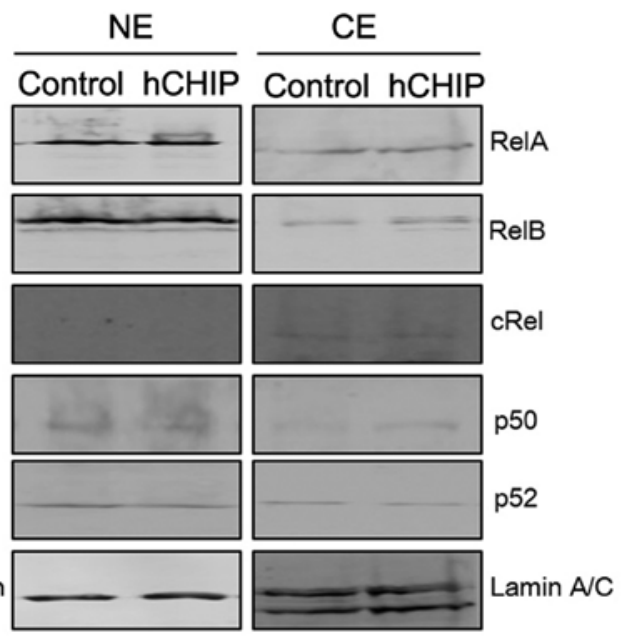

D

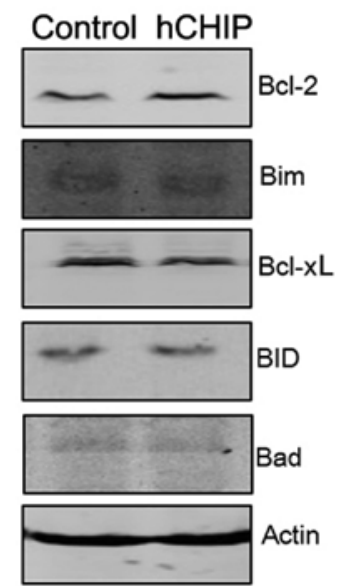

Figure 3. CHIP overexpression regulates proliferation- and apoptosis-associated proteins. (A) Protein expression levels of TRAF2 and TRAF3 were analyzed by western blotting. The level of each protein was normalized against actin. (B) The protein expression levels of nuclear factor- $\mathrm{\kappa} B$ subunits were analyzed by western blotting. Protein expression in the NE and CE portions were normalized against actin and laminA/C, respectively. (C) The expression levels of proteins associated with the AKT signaling pathway were analyzed by western blotting. The level of each protein was normalized against actin. (D) Expression levels of pro- and anti-apoptotic proteins were analyzed by western blotting. The level of each protein was normalized against actin. CHIP, carboxyl terminus of Hsc-70interacting protein; hCHIP, human CHIP; NE, nuclear extract; CE, cytoplasmic extract; TRAF, TNF receptor-associated factor; RelA, transcription factor p65; RelB, transcription factor RelB; cRel, proto-oncogene c-Rel; AKT, protein kinase B; p, phosphorylated; PDK, 3-phosphoinositide-dependent protein kinase; PTEN, phosphatase and tensin homolog; c-Raf, proto-oncogene c-Raf; GSK, glycogen synthase kinase; Bcl-2, B-cell lymphoma-2; Bim, Bcl-2-like protein 11; Bcl-xL, Bcl-extra large; BID, BH3 interacting-domain death agonist; Bad, Bcl-2-associated death promoter.

CHIP overexpression promotes the G0-G1 phase of the cell cycle. Cell-cycle analyses and cellular DNA content measurements were performed using PI staining. The percentages of cells in the G0-G1, S and G2-M cell-cycle phases were $66.56 \pm 0.41,16.15 \pm 0.826$ and $18.02 \pm 0.91 \%$ respectively in the DU145-control cells and $65.34 \pm 0.47,16.78 \pm 0.19$ and $18.53 \pm 0.64 \%$ in the DU145-hCHIP cells. No significant differences were observed between the DU145-hCHIP and DU145-control cells with regard to the proportions in the $S$ and G2-M phases. However, a significant difference was detected in the proportion of cells in the G0-G1 phase between the two cell lines $(\mathrm{P}<0.05)($ Fig. 4A). As shown in Fig. 4B, the levels of proteins regulated in the cell cycle were detected by western blotting. The results suggested that CHIP overexpression promoted the expression of cyclin-dependent kinase 2, cyclin D1 and cyclin D3, and inhibited the expression of the cell cycle inhibitory proteins p21 and p27. Therefore, it may be concluded that CHIP overexpression promoted the proliferation and G0-G1 transition of prostate cancer cells.

CHIP affects the migration ability of DU145 prostate cancer cells. The migration ability of the cells was examined in vitro using three different methods, namely a scratch healing assay, the real-time xCelligence system and a Transwell assay. In the scratch healing assay, the wound area was reduced to a greater extent by the CHIP-overexpressing cells than by the control cells (Fig. 5A). The real-time xCelligence system assay indicated that the DU145-hCHIP cells migrated faster than the DU145-control cells during the 24-h continuous monitoring, and statistically significant differences were detected between the two cell lines at 20 and $24 \mathrm{~h}$ (Fig. 5B). The Transwell cell migration assay also demonstrated that the overexpression of 

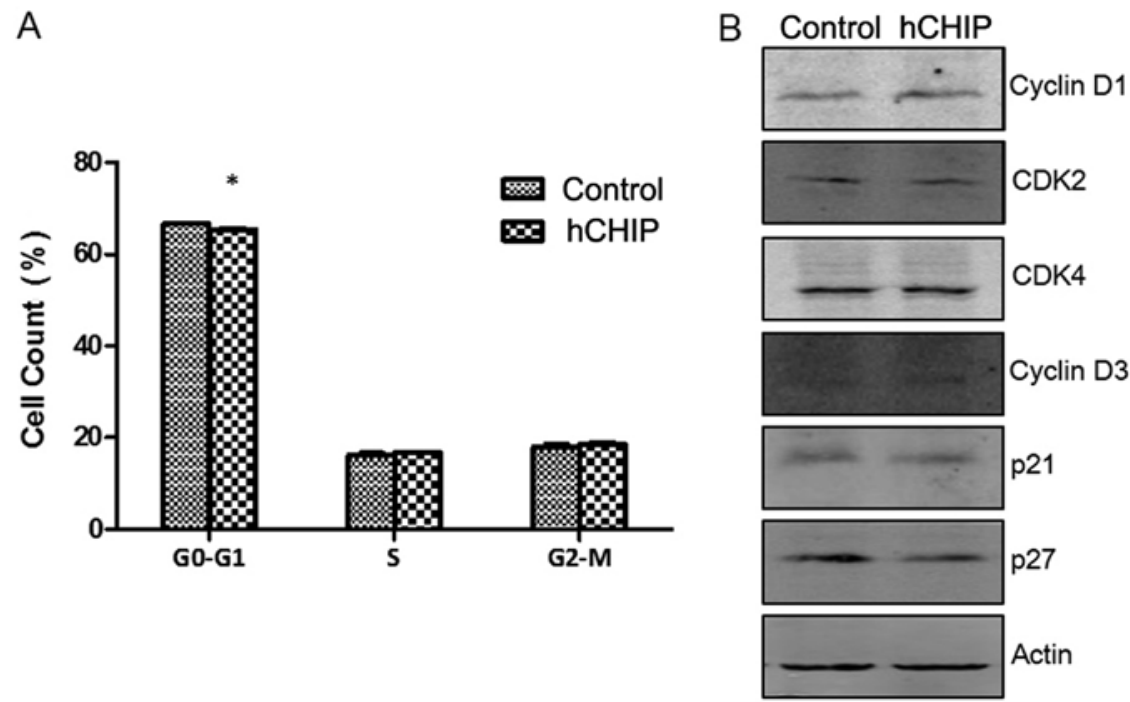

Figure 4. Overexpression of CHIP promotes the cell cycle. (A) Cell cycle analysis for the DU145-control and DU145-hCHIP cell lines was detected by flow cytometry. The bar chart represents the percentages of cells of the two established cell lines in three phases (G0-G1, S and G2-M). Significant differences were indicated ("P<0.05; Student's t-test). (B) The expression levels of cell cycle related-protein were detected by western blotting. The level of each protein was normalized against actin. CHIP, carboxyl terminus of Hsc-70-interacting protein; hCHIP, human CHIP; CDK, cyclin-dependent kinase.
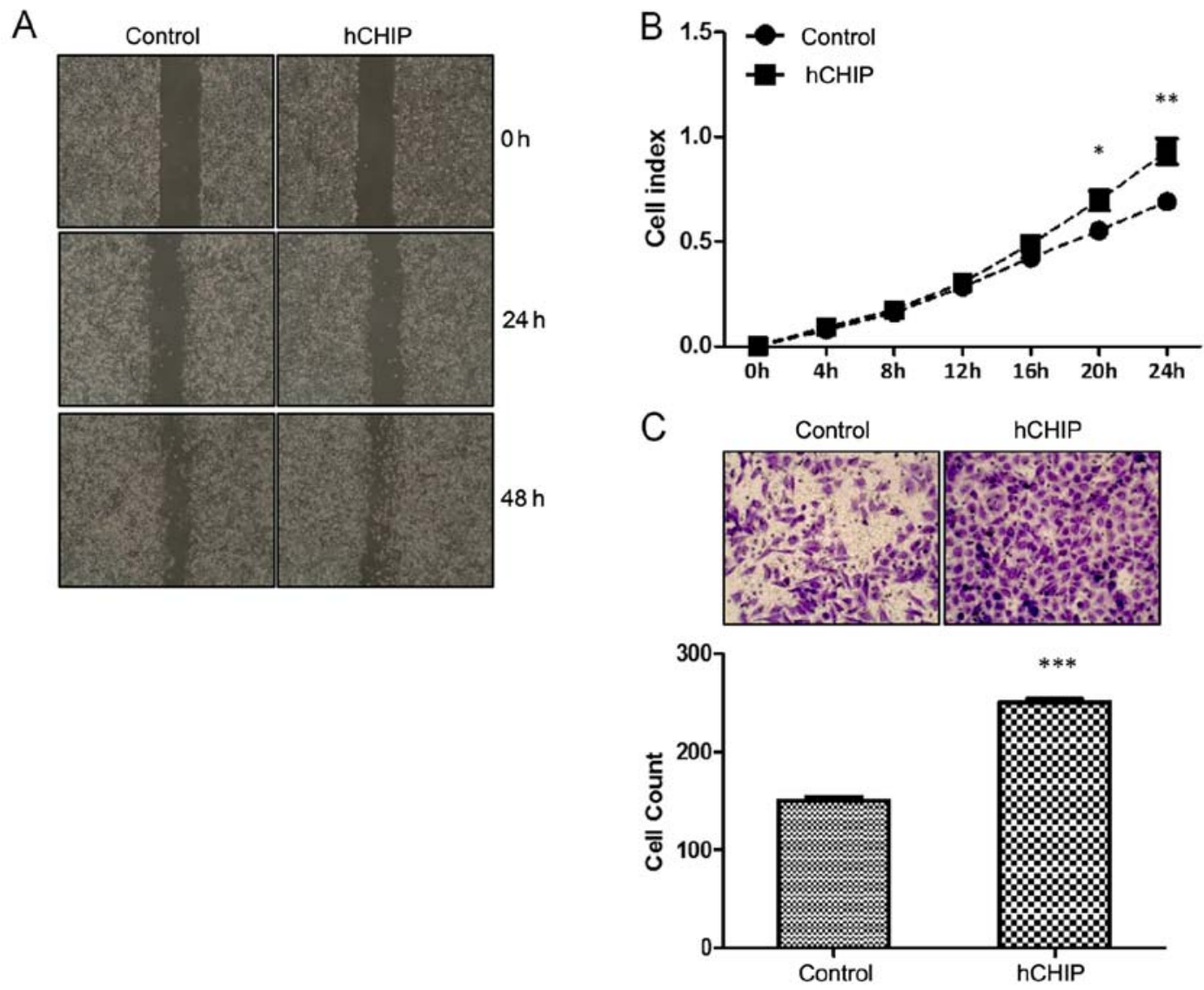

Figure 5. CHIP overexpression promotes the migration ability of DU145 cells. (A) The migration abilities of DU145-control and DU145-hCHIP cells were examined by a scratch healing assay at 0,24 and $48 \mathrm{~h}$. (B) The migration ability of cells was detected by a real-time xCelligence system. Each plate was inoculated with $4 \times 10^{4}$ cells and migration was examined during a $24-\mathrm{h}$ monitoring $\left({ }^{*} \mathrm{P}<0.05\right.$ and ${ }^{* *} \mathrm{P}<0.01$; Student's $\mathrm{t}$-test). (C) Transwell migration assay of the two established cell lines. The cells were cultured in Transwell chambers for $48 \mathrm{~h}$, then fixed and stained with crystal violet. The cells from five $20 \mathrm{x}$ fields were counted under a microscope and quantified results are presented $\left({ }^{* * * *} \mathrm{P}<0.001\right.$; Student's t-test). CHIP, carboxyl terminus of Hsc-70-interacting protein; hCHIP, human CHIP.

CHIP significantly increased the migration ability of the cells, as shown in Fig. 5C. Migratory cell numbers were increased $\sim 1.5$-fold $(\mathrm{P}<0.0001)$ for the DU145-hCHIP cells compared with the DU145-control cells (Fig. 5C). Therefore, it may 

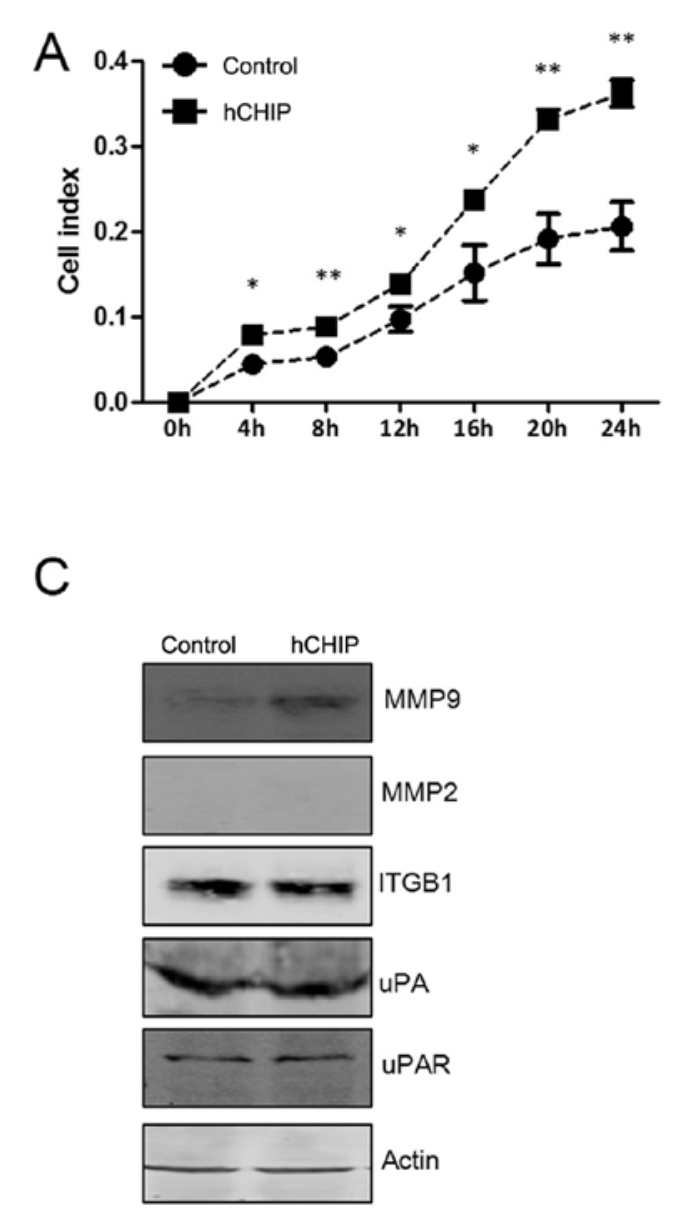
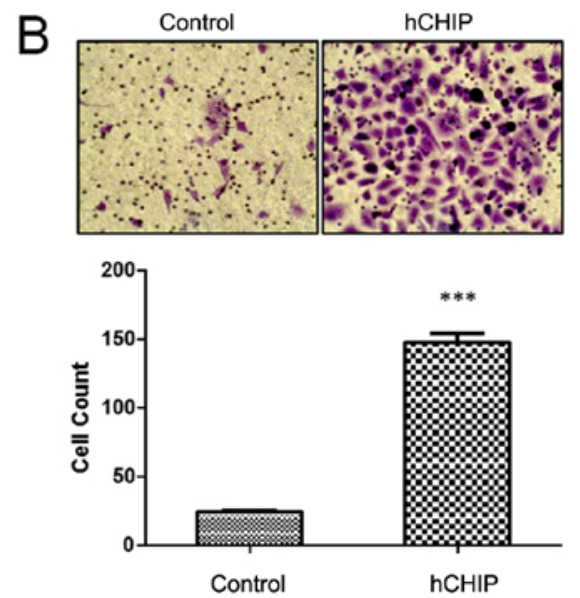

$\mathrm{D}$

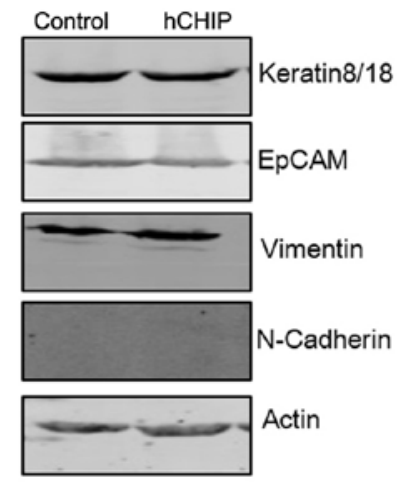

Figure 6. CHIP overexpression promotes the invasive ability of DU145 cells. (A) The invasive ability of cells was detected using a real-time xCelligence system. Each plate was inoculated with $6 \times 10^{4}$ cells and invasion was examined during a $24-\mathrm{h}$ monitoring ("P $<0.05$ and ${ }^{* *} \mathrm{P}<0.01$; Student's t-test). (B) Transwell invasion assay of the two established cell lines. The cells were cultured in Transwell chambers for $48 \mathrm{~h}$ and fixed and stained with crystal violet. The invaded cells from five 20x fields were counted under a microscope and quantified results are presented $\left({ }^{* * * *} \mathrm{P}<0.001\right.$; Student's $t$-test). (C) Protein expression levels of MMP9, MMP2, ITGB1, uPA and uPAR were analyzed by western blotting. The level of each protein was normalized against actin. (D) Protein expression levels of keratin8/18, EpCAM, vimentin and N-cadherin were analyzed by western blotting. The level of each protein was normalized against actin. CHIP, carboxyl terminus of Hsc-70-interacting protein; hCHIP, human CHIP; MMP, matrix metalloproteinase; ITGB1, integrin $\beta 1$; uPA, urokinase-type plasminogen activator; uPAR, uPA receptor; EpCAM, epithelial cell adhesion molecule.

be concluded that the overexpression of CHIP increased the migration ability of the DU145 prostate cancer cells.

CHIP affects the invasion ability of DU145 prostate cancer cells. To examine the effect of CHIP on the invasion ability of DU145 cells, the real-time xCelligence system was used and Transwell cell invasion assays were performed. As shown in Fig. 6A, the DU145 cells overexpressing CHIP invaded through the Matrigel faster than the control cells did, and there was a statistically significant difference between the cell index for the two cell lines during the 24-h continuous monitoring. In the Transwell assay, the invasive cells numbers were significantly increased $\sim 6$-fold $(\mathrm{P}<0.0001)$ for the DU145-hCHIP cells compared with the DU145-control cells (Fig. 6B).

MMP and uPA systems serve an important role in the invasion of tumor cells (16). In the present study, it was observed that the protein levels of MMP9 and UPAR were increased in the DU145-hCHIP cells compared with the DU145-control cells. However, no marked differences in the expression of MMP2 and UPA were detected. ITGB1 is associated with the function of invasion (17), and no difference in ITGB1 protein levels was evident between the two cell lines (Fig. 6C).
Epithelial mesenchymal transition (EMT) enables cancer cells to invade and migrate, finally resulting in metastasis (18). Biomarkers of the EMT process were investigated in the present study. The results demonstrated that CHIP overexpression upregulated the protein level of vimentin, which is a mesenchymal marker (19). As epithelial markers, the protein levels of N-cadherin, EpCAM and keratin8/18 (20-23) were not affected by the overexpression of CHIP (Fig. 6D). These results suggest that the overexpression of CHIP promoted the invasive ability of prostate cancer by inducing the EMT process.

CHIP expression in human prostate cancer tissues. The expression levels of CHIP in 90 pairs of prostate cancer tissues and adjacent tissues were detected by IHC. The expression of CHIP in the prostate cancer cells was compared with that in the cells adjacent to the cancer. Representative cases of CHIP expression in cancer tissues and adjacent tissues are shown in Fig. 7. Positive immunohistochemical staining for CHIP was present mainly in the cytoplasm and on the membrane of the prostate cancer cells and the expression of CHIP in the prostate cancer tissues was higher than that in the adjacent 
Table I. Association between CHIP expression as determined by immunohistochemistry and the clinical pathological characteristics of patients with prostate cancer.

\begin{tabular}{|c|c|c|c|c|}
\hline \multirow[b]{2}{*}{ Characteristics } & \multirow[b]{2}{*}{ Patients, n (\%) } & \multicolumn{2}{|c|}{ CHIP expression, $\mathrm{n}(\%)$} & \multirow[b]{2}{*}{ P-value } \\
\hline & & High & Low & \\
\hline All patients & 90 & $53(58.89)$ & $37(41.11)$ & \\
\hline Age $(\text { years })^{\mathrm{a}}$ & & & & 0.970 \\
\hline$\leq 70$ & $46(51.11)$ & 27 & 19 & \\
\hline$>70$ & $44(48.89)$ & 26 & 18 & \\
\hline Gleason score & & & & 0.005 \\
\hline $5-6$ & $29(32.22)$ & 11 & 18 & \\
\hline $7-10$ & $61(67.78)$ & 42 & 19 & \\
\hline
\end{tabular}

${ }^{a}$ The median (range) age of the patients was 70 (55-90) years. CHIP, carboxyl terminus of Hsc-70-interacting protein.
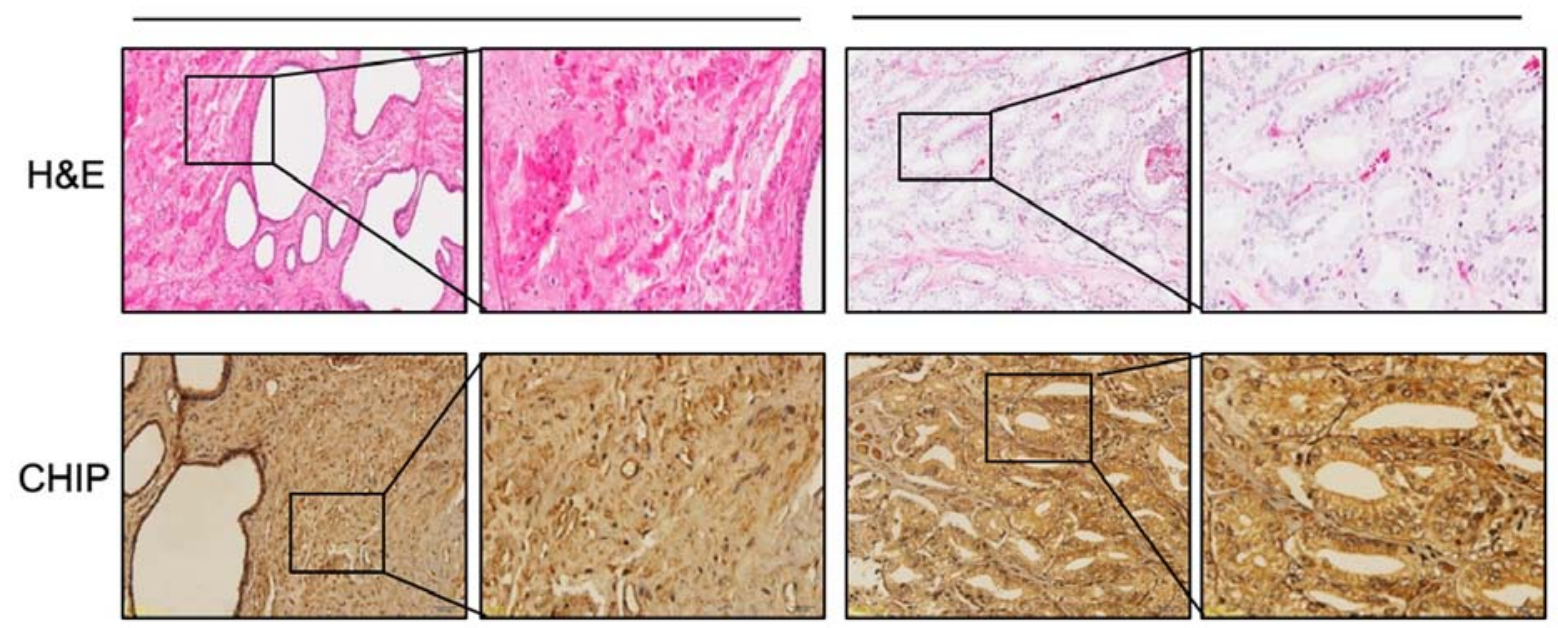

Figure 7. Representative cases of H\&E staining and CHIP expression in prostate cancer tissue and adjacent tissue to the cancer. Positive immunohistochemical staining for CHIP was detected primarily in the cytoplasm of the prostate cancer cells. Original magnification, x200 and boxed areas are shown at higher magnification, $x 400$. H\&E, hematoxylin and eosin; CHIP, carboxyl terminus of Hsc-70-interacting protein.

tissues. Overall, high staining of CHIP was detected in 53/90 $(58.89 \%)$ prostate cancer tissues, while relatively low staining of CHIP was detected in $37 / 90(41.11 \%)$ cancer samples. The association between CHIP expression and the clinical pathological characteristics of the prostate cancer patients is presented in Table I. The CHIP expression level exhibited a positive association with the Gleason scores of the prostate cancer patients $(\mathrm{P}<0.005)$, but did not differ according to the age of the patients $(\mathrm{P}=0.097)$. The results indicate that $\mathrm{CHIP}$ expression was increased in the prostate cancer tissue and that CHIP overexpression is an indicator of the cancer grade, and hence a poor prognosis.

\section{Discussion}

In the present study, CHIP was demonstrated to be important in the progression of prostate cancer. As an androgen-dependent cancer, prostate cancer is effectively treated by androgen withdrawal in the early stages. However, with progression of the disease, prostate cancer may become androgen-independent and resistant to hormone therapy (24). As androgen-independent cells, DU145 cells have a very low degree of differentiation and powerful migration and invasion abilities (25). In the present study, the overexpression of CHIP promoted cell proliferation and suppressed apoptosis in the DU145 prostate cancer cells, which was associated with activation of the AKT signaling pathway and the regulation of pro- and anti-apoptotic proteins. The migration and invasion of DU145 cells were also accelerated by the overexpression of CHIP, which was associated with the upregulation of MMP9 and UPAR. Furthermore, the present study revealed that overexpression of CHIP increased the protein level of vimentin, which is a mesenchymal marker, but not the protein levels of epithelial markers in the EMT process. In addition, evidence that increased CHIP expression is positively associated with a high histological grade of prostate cancer was obtained. Collectively, these results indicate that CHIP serves an oncogenic role in human prostate cancer.

CHIP is an E3 ubiquitin ligase and an HSP70 and HSP90 interacting co-chaperone. CHIP functions as a tumor suppressor in numerous types of tumors, including colorectal cancer, gastric cancer and breast cancer (26-28). However, there is also evidence to suggest that CHIP is a powerful 
oncogene in other types of tumors $(12,13)$. In the present study, the results indicated that CHIP functions as an oncogenic driver of prostate cancer cell proliferation. The forced expression of CHIP in DU145 cells increased cell proliferation by activation of the AKT signaling pathway, upregulation of p-PTEN and downregulation of PTEN. The AKT signaling pathway promotes the proliferation, migration and invasion of cancer cells and PTEN is a well-known suppressor of this pathway; however, PTEN can lose its tumor suppressor function by phosphorylation (29). It has previously been demonstrated that CHIP overexpression is associated with the phosphorylation of PTEN, which activates the AKT signaling pathway (30). In MCF7 and MCF10A human breast cancer cells, CHIP activates the AKT/forkhead box O3 (FoxO)/Bim signaling pathway to induce proliferation and apoptosis resistance by downregulating the level of PTEN (31). In human prostate cancer cells, the overexpression of CHIP leads to the accelerated degradation and elevated ubiquitination of endogenous PTEN, while the depletion of endogenous CHIP stabilizes PTEN (32). In thyroid cancer tissue and cell lines, the upregulation of CHIP increases the cell viability and growth via activation of AKT and MAPK pathways, while the downregulation of CHIP induces the opposite results (12). The present study demonstrated that the expression of PTEN was downregulated in DU145-hCHIP cells; however, the mechanism requires further exploration.

Previous evidence suggests that CHIP modulates mitotic arrest to suppress the proliferation of prostate cancer cells by degrading the androgen receptor in androgen-dependent LNCaP prostate cancer cells (33). In gastric cancer, CHIP overexpression promotes the ubiquitination and degradation of $\mathrm{p} 65$, which are canonical NF- $\mathrm{KB}$ signaling pathway activities, to inhibit the growth of xenografts and blood vessel formation in nude mice (27). In breast cancer cells, CHIP induces the downregulation of TRAF2 to inhibit NF-kB-mediated cell invasion (34). Unlike the previous findings, the present study indicated that CHIP had no association with the canonical or non-canonical NF- $\mathrm{KB}$ signaling pathways.

In the present study, CHIP-overexpression attenuated the apoptosis of the DU145 prostate cancer cells. The data revealed that Bcl-2, an anti-apoptotic protein, was markedly upregulated in the CHIP-overexpressing DU145 cells, whereas Bim, a pro-apoptotic protein, was downregulated. A previous study revealed that excessive CHIP expression promoted abnormal AKT activation, inactivated the FoxO3 signaling pathway and decreased the level of Bim (31). AKT phosphorylation releases Bcl-2 from the polymer to serve an anti-apoptotic function and decreases the proteins level of Bax and $\mathrm{Bad}(35,36)$. Bcl-2 and $\mathrm{Bcl}-\mathrm{xL}$ are anti-apoptotic members of the Bcl-2 family that regulate cell apoptosis. The results of the present study revealed no marked differences in the protein expression levels of $\mathrm{Bcl}-\mathrm{xL}$, but clear differences in the protein expression levels of Bcl-2. Although Bcl-2 and Bcl-xL have similar structural features (37), they undergo different changes in certain situations. It has been shown that the expression of $\mathrm{Bcl}-\mathrm{xL}$ is high in some hemopoietic tumors, while the expression of Bcl-2 is low (38). In present study, proliferation was significantly promoted and apoptosis was inhibited in the CHIP-overexpressing DU145 cells. These results are consistent with those reported in the previous studies.
Observation of cell cycle revealed that DU145-hCHIP cells went through the G0-G1 phase faster than DU145control cells. The western blotting results indicated that CHIP overexpression triggered the upregulation of cyclin D1 and the downregulation of p21 and p27. Cyclin D1, p21 and p27 are cell cycle-dependent regulatory factors that act as the downstream molecules of the AKT signaling pathway (39). Previous studies have indicated that the activated AKT pathway induces the expression of cyclin D1 to promote the cell cycle by the phosphorylation of GSK-3 $\beta(40,41)$. The AKT signaling pathway inhibits apoptosis and promotes cellular proliferation via the regulation of p27 and GSK-3 $\beta$ (42-44). CHIP is able to induce the ubiquitylation and degradation of p21, which leads to transient cell cycle arrest in the G1 phase (45). Previous studies suggested that the inhibition of CHIP upregulates the level of TGF- $\beta$-responsive p21 and p15 to affect cell cycle transition $(46,47)$. Cyclin D1 and p27 are directly modulated by the AKT signaling pathway at the transcriptional level to modulate cell proliferation (48-50). These observations lead to the conclusion that CHIP promoted the proliferation of prostate cancer cells via the promotion of cell cycle progression.

The high mortality rate of prostate cancer is associated with the high metastatic ability and invasive nature of this cancer (3). Degradation of the basement membrane barriers and the extracellular matrix (ECM) are crucial steps in the pathogenesis of prostate cancer (51). The functions of MMPs in the progression of tumor invasion and tissue remodeling have been confirmed (52). MMP2 and MMP9 are gelatinases and the two enzymes are relevant to the degradation of ECM through strong proteolytic activity (53). Previous studies indicated that high expression levels of CHIP are associated with the suppression of MMP9, which inhibits breast cancer invasion $(7,34)$. In a similar manner to MMPs, uPA and UPAR are vital determinants in the degradation of the EMC; studies indicate that UPAR acts as a single transducer that associates with certain cell surface molecules, such as integrin, in cell migration and adhesion (54-56). In DU145 and PC 3 cell lines, the downregulation of MMP9 and uPAR inhibited angiogenesis, Matrigel invasion and wound healing ability, and induced apoptosis (57). Consistently with the previous findings, the present study indicated that the upregulation of MMP9 and uPAR was associated with the increased migration and invasion ability of CHIP-overexpressing prostate cancer cell lines. However, CHIP did not appear to affect the expression levels of MMP2, ITGB1 and uPA.

EMT is a crucial process that changes epithelial cells to the migratory mesenchymal phenotype (19). During tumorigenesis, normal cancer cells acquire the ability to metastasize via EMT. In this procession, the acquisition of a mesenchymal phenotype by epithelial cells is accompanied by the upregulation of mesenchymal markers, including vimentin and $\mathrm{N}$-cadherin, and the downregulation of epithelial markers, including N-cadherin, EpCAM and keratin8/18 $(51,58)$. The present study demonstrated that CHIP overexpression upregulated the protein level of vimentin in DU145 prostate cancer cells, but did change the expression levels of $\mathrm{N}$-cadherin, EpCAM and keratin8/18. Therefore, it may be concluded that CHIP overexpression increases the expression of vimentin and thereby induces EMT. 
In the present study, the CHIP expression level was observed to be significantly elevated in prostate cancer tissues compared with normal tissue, and the expression level of CHIP was associated with the Gleason score, but not with age. These findings are in line with previous findings in gliomas and esophageal squamous cell carcinoma $(59,60)$. In view of the observation that CHIP is able to distinguish between different stages in the progression of prostate cancer, it may have potential as a clinical marker of prostate cancer.

In conclusion, CHIP overexpression significantly promoted the growth, migration and invasion of prostate cancer cells. The results of the present study suggest that CHIP effected the progression of proliferation in prostate cancer cells via downregulation of the expression of PTEN, which activated the AKT signaling pathway. Activation of the AKT signaling pathway significantly induced cell proliferation by facilitating cell growth, suppressing apoptosis and promoting G0-G1 transition. CHIP expression was positively associated with the ability of tumor cells to invade and migrate. CHIP possibly induced the EMT process in the prostate cancer cells to confer migratory and invasive properties to the cells. However, the molecular mechanism of CHIP in the process of migration and invasion required further elucidation. CHIP expression is associated with the Gleason scores of prostate cancer patients. High expression levels of CHIP were detected in prostate cancer tissues and were positively associated with high Gleason scores. These findings establish a tumor-promoting role for CHIP in the tumorigenesis of prostate cancer and have important implications for the diagnosis and therapy of this disease.

\section{Acknowledgements}

The authors greatly acknowledge Jingjing Xu and Jun Zhou for excellent technical assistance and suggestions.

\section{Funding}

The present study was supported by the Natural Science Foundation of Jiangsu Provincial (grant no. BK20151211).

\section{Availability of data and materials}

The analyzed data sets generated during the study are available from the corresponding authors on reasonable request.

\section{Authors' contributions}

LC performed research, collected and analyzed data. JZ performed research. HJD and FL collected clinical information. FG designed and performed research, collected, analyzed and interpreted data, and wrote the manuscript.

\section{Ethics approval and consent to participate}

Not applicable.

\section{Consent for publication}

Not applicable.

\section{Competing interests}

The authors declare that they have no conflicts of interest.

\section{References}

1. Siegel RL, Miller KD and Jemal A: Cancer Statistics, 2017. CA Cancer J Clin 67: 7-30, 2017.

2. Chen W, Zheng R, Baade PD, Zhang S, Zeng H, Bray F, Jemal A, Yu XQ and He J: Cancer statistics in China, 2015. CA Cancer J Clin 66: 115-132, 2016.

3. Litwin MS and Tan HJ: The diagnosis and treatment of prostate cancer: A review. JAMA 317: 2532-2542, 2017.

4. Paul I and Ghosh MK: The E3 ligase CHIP: Insights into its structure and regulation. BioMed Res Int 2014: 918183, 2014.

5. Murata S, Minami Y, Minami M, Chiba T and Tanaka K: CHIP is a chaperone-dependent $\mathrm{E} 3$ ligase that ubiquitylates unfolded protein. EMBO Rep 2: 1133-1138, 2001.

6. Paul I and Ghosh MK: A CHIPotle in physiology and disease. Int J Biochem Cell Biol 58: 37-52, 2015.

7. McDonough $\mathrm{H}$ and Patterson C: CHIP: A link between the chaperone and proteasome systems. Cell Stress Chaperones 8: 303-308, 2003.

8. Connell P, Ballinger CA, Jiang J, Wu Y, Thompson LJ, Höhfeld J and Patterson C: The co-chaperone CHIP regulates protein triage decisions mediated by heat-shock proteins. Nat Cell Biol 3: 93-96, 2001.

9. Shang Y, He J, Wang Y, Feng Q, Zhang Y, Guo J, Li J, Li S, Wang Y, Yan G, et al: CHIP/Stub1 regulates the Warburg effect by promoting degradation of PKM2 in ovarian carcinoma. Oncogene 36: 4191-4200, 2017.

10. Yonezawa T, Takahashi H, Shikata S, Liu X, Tamura M, Asada S, Fukushima T, Fukuyama T, Tanaka Y, Sawasaki T, et al: The ubiquitin ligase STUB1 regulates stability and activity of RUNX1 and RUNX1-RUNX1T1. J Biol Chem 292: 12528-12541, 2017.

11. 1Liu F, Zhou J, Zhou P, Chen W and Guo F: The ubiquitin ligase CHIP inactivates NF- $\kappa$ B signaling and impairs the ability of migration and invasion in gastric cancer cells. Int J Oncol 46: 2096-2106, 2015.

12. Zhang L, Liu L, He X, Shen Y, Liu X, Wei J, Yu F and Tian J: CHIP promotes thyroid cancer proliferation via activation of the MAPK and AKT pathways. Biochem Biophys Res Commun 477: 356-362, 2016.

13. Jin Y, Zhou L, Liang ZY, Jin KM, Zhou WX and Xing BC: Clinicopathologic and prognostic significance of carboxyl terminus of Hsp70-interacting protein in HBV-related hepatocellular carcinoma. Asian Pac J Cancer Prev 16: 3709-3713, 2015.

14. Livak KJ and Schmittgen TD: Analysis of relative gene expression data using real-time quantitative PCR and the 2(- $\Delta \Delta \mathrm{C}(\mathrm{T}))$ Method. Methods 25: 402-408, 2001.

15. Tang $X$, Zhang $L$ and Wei W: Roles of TRAFs in NF- $\kappa B$ signaling pathways mediated by BAFF. Immunol Lett 196: 113-118, 2018.

16. Mali AV, Joshi AA, Hegde MV and Kadam ShS: Enterolactone suppresses proliferation, migration and metastasis of MDA-MB-231 breast cancer cells through inhibition of uPA induced plasmin activation and MMPs-mediated ECM remodeling. Asian Pac J Cancer Prev 18: 905-915, 2017.

17. Kurozumi A, Goto Y, Matsushita R, Fukumoto I, Kato M, Nishikawa R, Sakamoto S, Enokida H, Nakagawa M, Ichikawa T, et al: Tumor-suppressive microRNA-223 inhibits cancer cell migration and invasion by targeting ITGA3/ITGB1 signaling in prostate cancer. Cancer Sci 107: 84-94, 2016.

18. Grant CM and Kyprianou N: Epithelial mesenchymal transition (EMT) in prostate growth and tumor progression. Transl Androl Urol 2: 202-211, 2013.

19. Nakazawa M and Kyprianou N: Epithelial-mesenchymal-transition regulators in prostate cancer: Androgens and beyond. J Steroid Biochem Mol Biol 166: 84-90, 2017.

20. Zhang T, Zhao G, Yang C, Dong P, Watari H, Zeng L, Pfeffer LM and Yue J: Lentiviral vector mediated-ASAP1 expression promotes epithelial to mesenchymal transition in ovarian cancer cells. Oncol Lett 15: 4432-4438, 2018.

21. Chaudhari PR, Charles SE, D'Souza ZC and Vaidya MM: Hemidesmosomal linker proteins regulate cell motility, invasion and tumorigenicity in oral squamous cell carcinoma derived cells. Exp Cell Res 360: 125-137, 2017. 
22. Nassour M, Idoux-Gillet Y, Selmi A, Côme C, Faraldo ML, Deugnier MA and Savagner P: Slug controls stem/progenitor cell growth dynamics during mammary gland morphogenesis. PLoS One 7: e53498, 2012.

23. Wu F, Zhu J, Mao Y, Li X, Hu B and Zhang D: Associations between the epithelial-mesenchymal transition phenotypes of circulating tumor cells and the clinicopathological features of patients with colorectal cancer. Dis Markers 2017: 9474532, 2017.

24. Szostak MJ and Kyprianou N: Radiation-induced apoptosis: Predictive and therapeutic significance in radiotherapy of prostate cancer (Review). Oncol Rep 7: 699-706, 2000.

25. Motta M, Dondi D, Moretti RM, Montagnani Marelli M, Pimpinelli F, Maggi R and Limonta P: Role of growth factors, steroid and peptide hormones in the regulation of human prostatic tumor growth. J Steroid Biochem Mol Biol 56: 107-111, 1996.

26. Wang Y, Ren F, Wang Y, Feng Y, Wang D, Jia B, Qiu Y, Wang S, $\mathrm{Yu}$ J, Sung JJ, et al: CHIP/Stubl functions as a tumor suppressor and represses NF- $\kappa \mathrm{B}-$ mediated signaling in colorectal cancer. Carcinogenesis 35: 983-991, 2014.

27. Wang S, Wu X, Zhang J, Chen Y, Xu J, Xia X, He S, Qiang F, Li A, Shu Y, et al: CHIP functions as a novel suppressor of tumour angiogenesis with prognostic significance in human gastric cancer. Gut 62: 496-508, 2013.

28. Tsuchiya M, Nakajima Y, Hirata N, Morishita T, Kishimoto H, Kanda Y and Kimura K: Ubiquitin ligase CHIP suppresses cancer stem cell properties in a population of breast cancer cells. Biochem Biophys Res Commun 452: 928-932, 2014.

29. Torres J and Pulido R: The tumor suppressor PTEN is phosphorylated by the protein kinase $\mathrm{CK} 2$ at its $\mathrm{C}$ terminus. Implications for PTEN stability to proteasome-mediated degradation. J Biol Chem 276: 993-998, 2001.

30. Brazil DP, Yang ZZ and Hemmings BA: Advances in protein kinase B signalling: AKTion on multiple fronts. Trends Biochem Sci 29: 233-242, 2004.

31. Lv Y, Song S, Zhang K, Gao H and Ma R: CHIP regulates AKT/FoxO/Bim signaling in MCF7 and MCF10A cells. PLoS One 8: e83312, 2013 .

32. Ahmed SF, Deb S, Paul I, Chatterjee A, Mandal T, Chatterjee U and Ghosh MK: The chaperone-assisted E3 ligase $\mathrm{C}$ terminus of Hsc70-interacting protein (CHIP) targets PTEN for proteasomal degradation. J Biol Chem 287: 15996-16006, 2012.

33. Sarkar S, Brautigan DL, Parsons SJ and Larner JM: Androgen receptor degradation by the E3 ligase CHIP modulates mitotic arrest in prostate cancer cells. Oncogene 33: 26-33, 2014

34. Jang KW, Lee KH, Kim SH, Jin T, Choi EY, Jeon HJ, Kim E, Han YS and Chung JH: Ubiquitin ligase CHIP induces TRAF2 proteasomal degradation and NF- $\mathrm{BB}$ inactivation to regulate breast cancer cell invasion. J Cell Biochem 112: 3612-3620, 2011.

35. Henshall DC, Araki T, Schindler CK, Lan JQ, Tiekoter KL, Taki W and Simon RP: Activation of Bcl-2-associated death protein and counter-response of Akt within cell populations during seizureinduced neuronal death. J Neurosci 22: 8458-8465, 2002.

36. Datta SR, Dudek H, Tao X, Masters S, Fu H, Gotoh Y and Greenberg ME: Akt phosphorylation of BAD couples survival signals to the cell-intrinsic death machinery. Cell 91: 231-241, 1997.

37. Roy MJ, Vom A, Czabotar PE and Lessene G: Cell death and the mitochondria: Therapeutic targeting of the BCL-2 family-driven pathway. Br J Pharmacol 171: 1973-1987, 2014.

38. Swanson PJ, Kuslak SL, Fang W, Tze L, Gaffney P, Selby S, Hippen KL, Nunez G, Sidman CL and Behrens TW: Fatal acute lymphoblastic leukemia in mice transgenic for B cell-restricted Bcl-xL and c-myc. J Immunol 172: 6684-6691, 2004.

39. Lee JT, Lehmann BD, Terrian DM, Chappell WH, Stivala F, Libra M, Martelli AM, Steelman LS and McCubrey JA: Targeting prostate cancer based on signal transduction and cell cycle pathways. Cell Cycle 7: 1745-1762, 2008.

40. Alan Diehl J, Cheng M and Martine F: Roussel and Sherr CJ: Glycogen synthase kinase-3b regulates cyclin D1 proteolysis and subcellular localization. Genes Dev 12: 3499-3511, 1998.
41. Shaw M, Cohen $\mathrm{P}$ and Alessi DR: The activation of protein kinase $\mathrm{B}$ by $\mathrm{H}_{2} \mathrm{O}_{2}$ or heat shock is mediated by phosphoinositide 3-kinase and not by mitogen-activated protein kinase-activated protein kinase-2. Biochem J 336: 241-246, 1998.

42. Zhang BG, Li JF, Yu BQ, Zhu ZG, Liu BY and Yan M microRNA-21 promotes tumor proliferation and invasion in gastric cancer by targeting PTEN. Oncol Rep 27: 1019-1026, 2012.

43. Vazquez F, Ramaswamy S, Nakamura N and Sellers WR: Phosphorylation of the PTEN tail regulates protein stability and function. Mol Cell Biol 20: 5010-5018, 2000.

44. Hill R and Wu H: PTEN, stem cells, and cancer stem cells. J Biol Chem 284: 11755-11759, 2009.

45. Biswas K, Sarkar S, Du K, Brautigan DL, Abbas T and Larner JM: The E3 ligase CHIP mediates p21 degradation to maintain radioresistance. Mol Cancer Res 15: 651-659, 2017.

46. Canaff L, Vanbellinghen JF, Kanazawa I, Kwak H, Garfield N, Vautour L and Hendy GN: Menin missense mutants encoded by the MEN1 gene that are targeted to the proteasome: Restoration of expression and activity by CHIP siRNA. J Clin Endocrinol Metab 97: E282-E291, 2012.

47. Massagué $\mathrm{J}$ and Gomis RR: The logic of TGFbeta signaling. FEBS Lett 580: 2811-2820, 2006

48. Zhou W, He MR, Jiao HL, He LQ, Deng DL, Cai JJ, Xiao ZY, Ye YP, Ding YQ, Liao WT, et al: The tumor-suppressor gene LZTS1 suppresses colorectal cancer proliferation through inhibition of the AKT-mTOR signaling pathway. Cancer Lett 360: 68-75, 2015.

49. Roy SK, Srivastava RK and Shankar S: Inhibition of PI3K/AKT and MAPK/ERK pathways causes activation of FOXO transcription factor, leading to cell cycle arrest and apoptosis in pancreatic cancer. J Mol Signal 5: 10, 2010.

50. Cui YM, Jiang D, Zhang SH, Wu P, Ye YP, Chen CM, Tang N, Liang L, Li TT, Qi L, et al: FOXC2 promotes colorectal cancer proliferation through inhibition of FOXO3a and activation of MAPK and AKT signaling pathways. Cancer Lett 353: 87-94, 2014.

51. Singh M, Yelle N, Venugopal C and Singh SK: EMT: Mechanisms and therapeutic implications. Pharmacol Ther 182: 80-94, 2018.

52. Werb Z: ECM and cell surface proteolysis: Regulating cellular ecology. Cell 91: 439-442, 1997.

53. Lukaszewicz-Zajac M, Mroczko B and Szmitkowski M: Gastric cancer - The role of matrix metalloproteinases in tumor progression. Clin Chim Acta 412: 1725-1730, 2011.

54. Rao JS: Molecular mechanisms of glioma invasiveness: The role of proteases. Nat Rev Cancer 3: 489-501, 2003.

55. Dass K, Ahmad A, Azmi AS, Sarkar SH and Sarkar FH: Evolving role of uPA/uPAR system in human cancers. Cancer Treat Rev 34: 122-136, 2008

56. Yuan ZL, Guan YJ, Chatterjee D and Chin YE: Stat3 dimerization regulated by reversible acetylation of a single lysine residue. Science 307: 269-273, 2005.

57. Nalla AK, Gorantla B, Gondi CS, Lakka SS and Rao JS: Targeting MMP-9, uPAR, and cathepsin B inhibits invasion, migration and activates apoptosis in prostate cancer cells. Cancer Gene Ther 17: 599-613, 2010.

58. Gurzu S, Turdean S, Kovecsi A, Contac AO and Jung I: Epithelial-mesenchymal, mesenchymal-epithelial, and endothelial-mesenchymal transitions in malignant tumors: An update. World J Clin Cases 3: 393-404, 2015.

59. Xu T, Zhou Q, Zhou J, Huang Y, Yan Y, Li W, Wang C, Hu G, Lu Y and Chen J: Carboxyl terminus of Hsp70-interacting protein (CHIP) contributes to human glioma oncogenesis. Cancer Sci 102: 959-966, 2011.

60. Wen J, Luo KJ, Hu Y, Yang H and Fu JH: Metastatic lymph node CHIP expression is a potential prognostic marker for resected esophageal squamous cell carcinoma patients. Ann Surg Oncol 20: 1668-1675, 2013. 